\title{
RAPID DEVELOPMENT OF VIRTUAL REALITY BASED CONSTRUCTION SEQUENCE SIMULATIONS: A CASE STUDY
}

SUBMITTED: February 2019

REVISED: August 2019

PUBLISHED: January 2020 at https://www.itcon.org/2020/4

EDITOR: Kumar B.

DOI: $10.36680 /$ j.itcon.2020.004

\author{
Jason Lucas \\ Associate Professor, Nieri Family Department of Construction Science and Management, \\ Clemson University, USA \\ jlucas2@clemson.edu
}

SUMMARY: Virtual Reality (VR) is a powerful tool for providing active and interactive learning experience for students where real-life physical conditions are not available. Visualizations of construction sequencing of components have been identified as an area where VR can enhance student learning. VR simulations allow students a flexible learning environment for them to explore without restrictions of timing physical site visits or inherent dangers of an active construction project. One of the barriers for widespread use of VR in the construction classroom is the lack of available content. This paper explores the development of a framework for rapid content development that can help students develop an understanding of the sequence and components of construction assemblies. The framework and necessary model development is discussed with initial responses from students to a pilot test of the simulations in the classroom.

KEYWORDS: virtual reality, simulation, construction education, construction methods.

REFERENCE: Jason Lucas (2020). Rapid development of Virtual Reality based construction sequence simulations: a case study. Journal of Information Technology in Construction (ITcon), Vol. 25, pg. 72-86, DOI: 10.36680/j.itcon.2020.004

COPYRIGHT: (C) 2020 The author(s). This is an open access article distributed under the terms of the Creative Commons Attribution 4.0 International (https://creativecommons.org/licenses/by/4.0/), which permits unrestricted use, distribution, and reproduction in any medium, provided the original work is properly cited. 


\section{INTRODUCTION}

Experiential learning, through hands-on engagement, is beneficial for students in a construction management curriculum because it enhances students' fundamental conceptual understanding of material (Davis and Cline, 2009). Typical means of experiential learning for construction management students include service learning projects like Habitat for Humanity (Cho et al, 2015), hands-on laboratory to supplement classroom learning (Jin and Nakayam, 2013), and internships (Moore and Plugge, 2008). When used to augment classroom based learning and content, experiential learning has been shown to enhance comprehension of concepts and applying the knowledge to the real world (Hegazy et al, 2013). When real work activities are not possible do to limitations of resources, simulated learning environments have been examined as a method for experiential learning. Simulated games have helped improved the traditional classroom experience by providing students a better understanding of concepts and how to apply those concepts to real-world applications (Hamzeh, 2017). Simulated training and learning environments have been identified as effective means of learning skills, especially when learners have appropriate supervisory support to provide motivation and confidence (Douglas-Lenders et.al, 2017). Enhanced simulations for experiential learning can be made possible with Virtual Reality.

Virtual Reality (VR) is a computer simulated environment that allows for user interactions in a virtual world. When properly developed, VR can provide students with an active learning environment (Sala, 2016). Comprehensive learning in a 3D virtual environment allows learners to retain more complex concepts of 3D phenomena as opposed to other forms of conceptualization (Roussou et al, 2006). This is attributed to the user's ability to freely navigate and engage the environment and learn by exploring and observing complexities of the environment that are not otherwise easily understood (Winn et al, 2002). uccess of the experiential learning depends on the types of tasks that the user is performing and vividness and level of realism of the environment (Kwon, 2018).

When comparing methods of experiential learning Jin and Nakayama (2013) found that providing students in an engineering occupational safety course with a lecture and VR simulation allowed for the same level of learning as a lecture with a physical lab experience in terms of understanding safe operation of the equipment. Both methods allowed for enhanced understanding over a "lecture only" experience (Jin and Nakayama, 2013). VR in the classroom can provide a blended learning environment, allow for learning that is more efficient, improve recall of information, and provide an experiential learning tool to transfer perceived knowledge to practice (Maghool et al, 2018).

Additional environmental conceptualization may be possible with immersive VR. Immersive VR places the user is completely in the environment through the means of a Head Mounted Display (HMD) or Cave Automatic Virtual Environment (CAVE). Immersive VR provides a sense of presence in a place where they are not physically located. Immersive environments provide positive effects on cognition in terms of memory recall because immersion within the environment makes the brain encode experiences much like they were physically happening (Repetto et al, 2016). Immersive VR has been utilized in various domains for education and training when time, inaccessibility of the physical event, safety due to dangerous situations, and ethical concerns are barriers to students participating in the actual event (Freina \& Ott, 2015). Immersive experiences create a higher level cognitive encoding within the working memory of the brain which correlates to greater cognitive retrieval over time (Jaiswall et al, 2010). Not only can VR and immersive VR improve student cognition but virtualized 3D environments have also been shown to increase learners' motivation in learning skills and concepts (Winn et al, 2002). VR training has been found more effective in maintaining trainees' attention and concentration (Perlman and Barak, 2013). Shu et al (2018) identified that user performance and understanding of content was improved with the use of HMDVR as opposed to computer screen based VR simulation. They believed that user involvement of moving their head to move around the space and moving their arms to select things and pick things up, as opposed to just using the mouse and keyboard, helped the user have a better sense of presence and self-efficacy within the simulation thus providing a better understanding of the scenario (Shu et al, 2018).

It is with this in mind that immersive VR has been explored as a method for students to visualize 3D environments and construction sequence in an undergraduate Materials and Methods classroom as part of a construction management curriculum. Due to the lack of time within the class schedule to allow for multiple site visits and the lack of hands-on lab space and resources to create multiple physical mock-ups, VR has proven to be a promising and viable alternate solution. 
Preliminary studies have shown that students see value in the use of VR to support classroom based learning. Students have identified VR as a potential medium to provide better visualization of building processes, understanding of complex assemblies, participation in virtual site visits, and exploring construction sequences and processes (Lucas, 2018a). Additionally, students identified that VR environments allowed for better understanding of spatial features, material usage, scale, and assembly of components when compared to traditional classroom methods of rendered images, pictures, and videos (Lucas, 2018b). To expand on the preliminary study an immersive VR module was created to demonstrate the construction sequence and related assemblies of a wood framed structure. This paper discusses the processes of creating the virtual learning module, the framework for rapidly developing content, and preliminary results of using the simulation in the classroom.

\section{BACKGROUND OF VR IN DESIGN, CONSTRUCTION, AND EDUCATION}

Prior uses of VR and simulation for design and construction have been developed to help students increase awareness and advance their understanding of complex conditions in structural design, construction management processes, safety, and spatial orientation. The technology has long been of interest as a means to enhance the educational experience of students in multiple domains.

Fogarty et al (2015) utilized both CAVE-type VR (Cave Automatic Virtual Environment) and HMD-VR (Head Mounted Display) to substitute for limitations in hands-on lab space for students in a structural lab. Students were able to learn about structural components and assemblies in a virtual environment outfitted with dynamic models to demonstrate structural concepts. Luo and Chhabda (2018) also developed online virtual lab modules for structural design and analysis that allowed students to customize designs and test them within a virtual lab to see how they reacted to various loading conditions. Both offered students means to explore concept and what-if scenarios that were not possible in a traditional classroom lab setting.

Related to construction management processes, Messner et.al. (2003) developed a system within a CAVE environment to allow students to review 4D Simulations. Results included observations that students provided better critiques of the models they and others made in the full-scale virtual environments as opposed to 2D representations of the model. Pariafsai (2016) developed an interactive game to teach construction management processes that helped improve students' problem solving and critical thinking skills. Related to construction methods and assemblies of bridges, Sampaio et.al. (2010) utilized a model that can easily be deconstructed in a virtual environment to enhance students' understanding of components of design.

3D simulation and VR have also been explored in construction safety. Immersive VR allowed for placing new trainees in virtual unsafe work scenarios to test human behaviour to the unsafe conditions that are commonly found in practice (Hilfert et al, 2016). Jin and Nakayama (2013) incorporated virtual 3D safety exercises into an engineering technology program to help students better understand safety in a laboratory setting. Another study examined the use of VR with hazard inspection and recognition within a VR environment (Le et al, 2014). Zhao and Lucas (2015) examined the use of VR simulations for training related to electrical hazards. Additionally, Pedro et.al. (2016) incorporated virtual content to compliment traditional lectures in a construction materials classroom to integrate safety information through mobile based virtual simulations. Preliminary findings were reported as benefiting students' understanding of safety concepts on a dynamic jobsite.

When examining architectural students' understandings of perception of space it was found that a larger scale, immersive projection allowed for a more favourable perception of space than a non-immersive VR system on a work station (Paes et al, 2017). These findings are similar to case study observations where CAVE-like VR projection systems were utilized for client and user design review in healthcare design that showed benefits of greater understanding of spatial conditions by the future occupants of the facility after being immersed in the environment (Lin, 2018).

Even within the construction industry VR has been used to explore complex spatial situations and enhance visualization of construction elements. Bolton (2018) explored the use of VR for 4D-based collaborative constructability analysis and review through the development of a comprehensive, structured framework. Virtual reality and dynamic simulations were also utilized to link construction process simulation to landscape architecture design with interactive virtual software (Ma and Xia, 2017). 


\section{METHODOLOGY}

Since VR simulations have the ability to offer an experiential and active learning experience for students to visualize and understand complex three dimensional conditions, it is being explored as a supplement to classroom learning in construction education for a materials and methods class. The classroom experience for the Materials and Methods of Construction courses at Clemson University have traditionally been 2D media with samples of some materials that offered minimal hands on learning. Because of resource and space constraints, physical mockups were not viable. Additionally, due to time restrictions, field trips to observe actual construction in person were limited. Students within the program are required to have internship experience as part of their graduation requirements but at the time of the course offering the students had not completed the requirement or if they have experience there was no way to directly link their unstructured internships with the material of the structured course. Therefore, virtual reality simulations were explored as a substitute for hands-on experiential learning.

A major barrier to VR use in the classroom was lack of relevant content to support the classroom format. This research documents efforts to provide relevant content to support students learning of sequencing and assemblies of construction. The goal of the research was to rapidly develop useable simulations for the materials and methods class. The objectives for this study included:

1. Creating methods for simulation interactions that would provide students with a means of expanding their knowledge and comprehension of construction sequencing and assemblies.

2. Developing a flexible framework within the game engine software that would allow for rapid creation of simulations of different assemblies.

3. Ensuring minimal required customized coding to allow for simplicity in developing additional simulations to quickly develop new content as new models were created.

4. Testing the effectiveness of the VR simulations in augmenting student understanding of the material.

The research was broken into multiple parts (Figure 1). The first was to perform a preliminary study to address Objective \#1 and ensure that what was created would be something the students would be able to use and learn from. The students' perceptions of VR and comfort level of using the VR technology were documented. With positive results from the preliminary study a conceptual framework for developing the simulations was designed and developed. When the prototype simulation was created, care was taken to ensure that Objectives \#3 was taken into consideration. Objective \#4 will be tested as a part of future research.

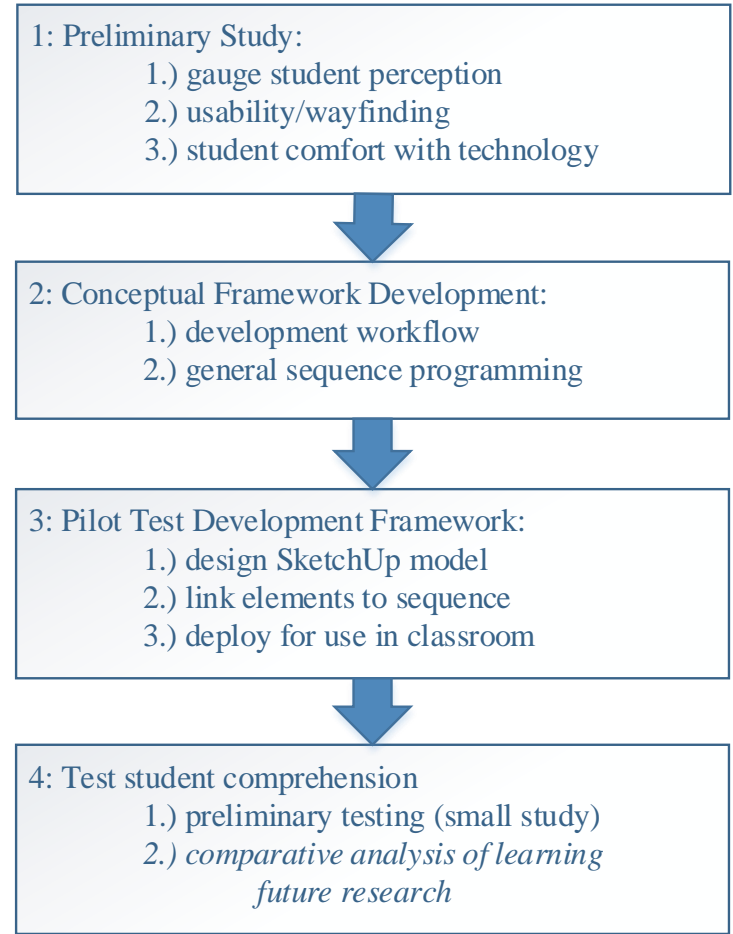

Objective 1: Methods usable by students for simulation

Objective 2: Develop flexible framework for us with different assebmlies

Objective 3: Ensure quick development with minimal customization

Objective 4: Testing student comprehension and affects on learning with simulation

Fig. 1: Research Methodology 


\subsection{Preliminary Studies}

Before any major development was done in terms of creating the simulated environments a preliminary study was completed to identify the following:

1. How students would respond to VR in the construction undergraduate classroom

2. Comfort level of students using the VR technology for learning and self-exploration

3. Best navigation and wayfinding techniques through a model for the student population

A simple model of a framed assembly was created from Sketchup and deployed to a Samsung GearVR headset utilizing Unity for the preliminary studies (Author, Year). The study consisted of three steps of interaction on behalf of the participating students: 1.) a pre-VR use survey to document demographics, prior experience levels of using VR, and preconceptions about VR use, 2.) a VR demonstration where students were able to virtually navigate through the model, and 3.) a post-VR use survey to gauge student reactions.

As a result of the preliminary study the majority of the students were very positive to the idea of using VR to augment construction education. The top potential use listed was for assembly visualization and understanding construction sequences. They also indicated that the use of a navigable virtual environment provided them a better understanding of space, details of assemblies, and material usage than photos and videos used in traditional classroom methods. Some of this may simply be due to the use of new technology, however many students indicated that they liked the control the VR simulation gave them over what they saw in the environment as opposed to static renderings or defined animations. Lastly, the preliminary study was used to gauge the susceptibility of students to cyber-sickness with this type of application. Cyber-sickness, or simulation sickness, is similar to motion sickness where the brain senses movement while other physiological sensors in the body indicate that you are not moving, thus causing queasiness, dizziness, vertigo, or general discomfort (LaViola, 2000; Dennison et al, 2016). Most students acknowledged minimal to no issues with discomfort as a result of participating in the preliminary study with no one experiencing major discomfort (Author, Year).

\subsection{Content Development Framework}

Once students have expressed their interest and acceptance of utilize the simulations as a potential learning tool a content development framework was created. Flexibility of the design was important to allow for incorporating various models of different assembly components without the need for massive amounts of customized programming. Since construction sequences are very additive processes this allowed for a simple conceptual model within the framework of turning elements "on", or make them visible, when they were put in place. Unless if temporary systems, such as scaffolding, are included in part of the simulation, components are installed over the existing components which allow elements to be made visible when necessary to depict the sequence of assembly. The framework was developed utilizing coding to turn selected elements "on" to make them visible within the simulation as specific trigger buttons are pushed. This allows for rapidly developing simulations of virtually any model by identifying which elements within the model should be turned on in each step of the sequence.

The schematic steps of the framework (Figure 2) include:

1. Model development, for the purposes of the study models were developed in SketchUp, the model was developed in a way that grouped the elements of the model in layers based on each step of the sequence.

2. Importing the model into Unity (game engine) with grouped element to match the sequence.

3. Linking components of the model to each step of the sequence array that was defined during the pilot simulation development.

4. Deploying the simulation for use with a compatible platform which includes both desktop and HMDbased Samsung GearVR versions.

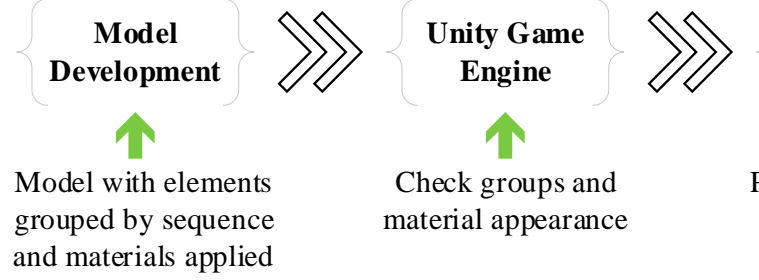

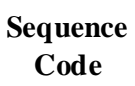

Put groups in order

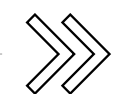

Deploy Simulation

Fig. 2: Schematic framework for VR content development 


\subsubsection{Model Development}

The models for the study were developed using SketchUp for two reasons. The first is the ease of which SketchUp models can be utilized within Unity. The second was the fact that an accurate geometric representation of the assembled components was needed more so than a complex building information model that contained data and parameters that are unusable within Unity.

SketchUp models saved as version 8 or earlier can be imported into the Unity development software as an asset without any additional processing of the model components. Attributes of the model, including material references, are brought into Unity as part of the model asset. Additionally, any element from the SketchUp model can have its properties modified directly in Unity without going back to the original source model and reimporting an updated model. The hierarchy of elements is left intact. Models from other software, such as Revit, would need to be exported to specific file formats and materials applied either within Unity or an intermediary software. Since only the geometries were needed, SketchUp was identified as the most appropriate choice for model development.

Additionally, a detailed model that clearly shows components and materials was needed. This required that each framing member, among other elements, be represented in the model. Another reason why SketchUp was used is there was only a need for clear accurate graphic representation of the elements and no need for parametric properties and complexities that are in a more developed building information model. Having the elements modelled individually in a geometric modelling software such as SketchUp easily allowed for the visual manipulations of elements over more advanced parametric based modelling software.

For any model developed to work with the framework, the layers (or groups) of elements created in the model need to correspond with the level of detail planned for the simulation. The model can have multiple layers that end up in one group within the simulation, but breaking a layer up within Unity is not as easy. A model that has more details than needed would be easier to utilize in Unity than a model that does not have enough detail. For example, if the intent is to show the assembly of a wood framed wall, the model would need to have separate layers for the wood studs, insulation, drywall, sheathing, and finishes to be useful within Unity. This would allow each layer to be treated as elements within Unity. If sheathing was included with the stud wall elements on the same layer it would be difficult to have them show up as separate steps within the model because Unity would treat it as the same element. It is easier to combine multiple elements that are input into a GameObject then split the layers within Unity.

For the pilot development a detailed model of a wood framed building was developed. The model including the foundation system, all framing components, rough-in components for mechanical, plumbing, and electric, insulation, and finishes for both the exterior and interior. The elements within the model were grouped together. Similarly, the elements can be placed on the same level (Figure 3).

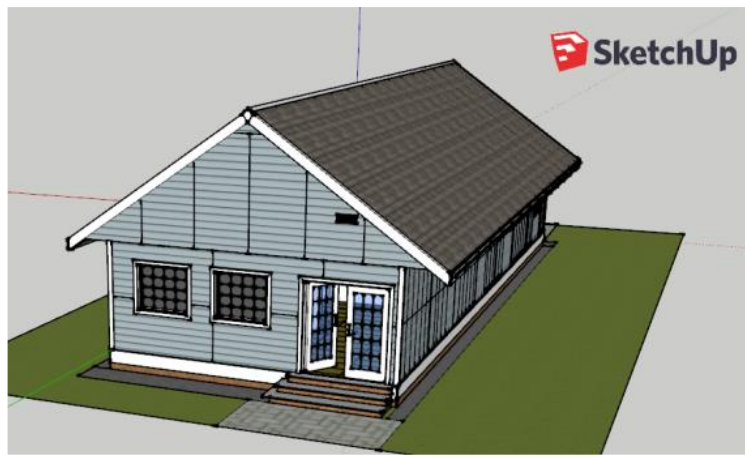

Model Developed
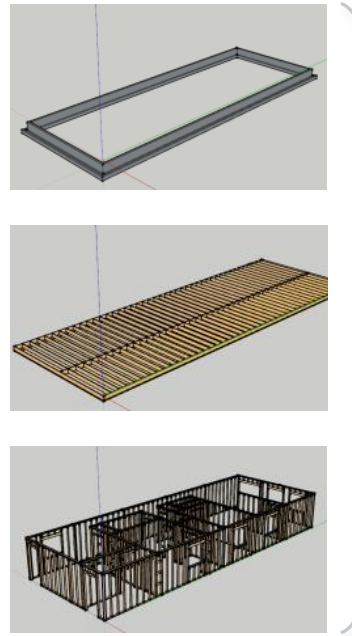

Model Components Grouped by Sequence Step Ex: Foundation, Floor Framing, Wall Framing, etc.

Fig. 3: Model developed and broken by sequence group 


\subsubsection{Game Engine Environment}

A SketchUp model can be imported into the Unity programming environment as a model asset. The elements of the model keep the same hierarchy and attributes from SketchUp and appear within the project navigator window. The hierarchy of the model when it is imported into Unity matches the layers that were used to develop the model in SketchUp. Furthermore, if groups of elements are placed on a layer they will show up as a child asset of the element within the environment hierarchy. Additionally, empty GameObjects can be created in Unity and the programmer can group modelled components under the GameObjects to change the hierarchy or modify the organization of the modelled elements without having edit the original model. Anything within a GameObject can be treated as one object entity when it comes to controlling element behaviours in the simulation. Material mapping is transferred from the SketchUp model, however new materials can be defined in Unity and mapped to elements within the model. Modifications to how components visually appear are easily accomplished within the game engine environment.

Within Unity, all elements within the environment are shown in the scene navigation window. Any level of the hierarchy can be treated as a "GameObject" or a new "GameObject" can be created to group multiple components directly in Unity. For instance, in Figure 4, a group of "Floor_Framing_Complete" was created as a group in SketchUp. This group can be treated as a GameObject within Unity, however in the example shown a separate GameObject of "Floor Joists" is shown which houses the group of modelled objects from SketchUp and some other related modelled objects that were not in the original group. The appearance and behaviour of the GameObject can then be controlled through other programing within Unity. Any element within the model can also be treated as a GameObject to allow for programming functionality and controlling appearances of the element. Sub-elements within the hierarchy of any GameObject that is controlled through the game engine inherit the same functionality as the parent GameObject.

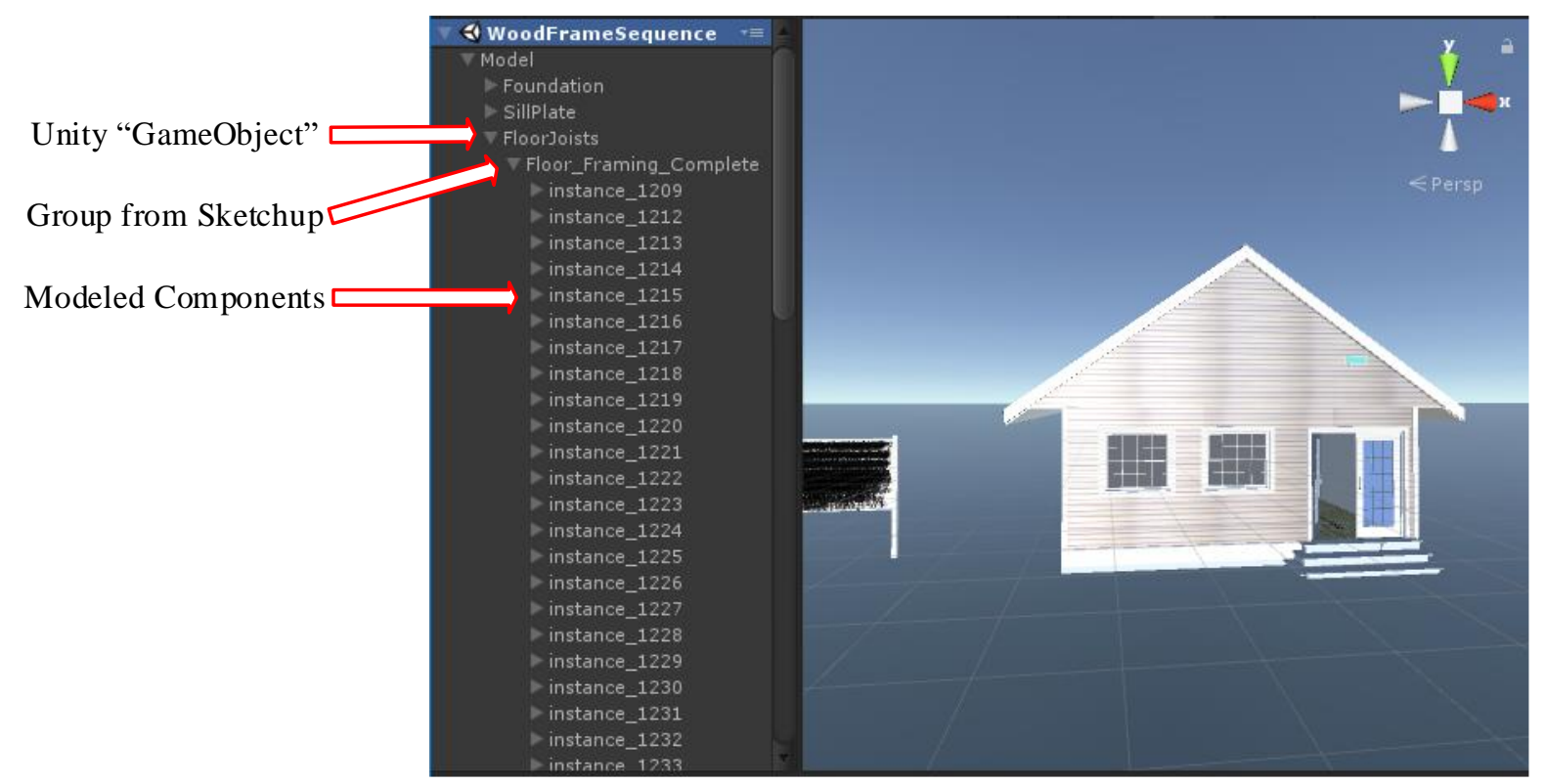

Fig. 4: Model in Unity

\subsubsection{Sequence Programming}

In order to create the sequencing portion of the simulation, a C\# code method was created. The method acts as an asset within Unity and can be connected to any GameObject. For the purposes of the framework it was connected to the "Ground Plane" object in the model. When the simulation is executed, the method is run and creates an array to store game objects. The C\# method creates an array of objects and a counter set at zero (0). The "Sequence" array is a place holder for the groups of modelled elements used for the simulation. The counter is used to identify the step of the simulation that is active. The method is also coded to set the SetActive property of all elements in the array of elements to "off" so they are not visible to the user at the start of the simulation. 
When first developing a simulation with a new model within the framework, the "Sequence" array needs to be defined. The array is customized for the elements of the model to show the sequence steps of the simulation (Figure 5). Groups of modelled components treated as GameObjects are linked to the array elements. Some preparation in how the model is created and organized is required to streamline the process. In the example shown for the model of a small wood frame residence all elements that represent one step in the sequence were grouped in the same GameObject. For instance, the simulation shows that the "Foundation" will go in place first. The elements that made up the foundation walls and footings were grouped in layers within SketchUp and then placed in the same GameObject represented in the model hierarchy as "Foundation". This GameObject can then be dragged from the asset window to the "Sequence" array as "Element 0". The "size" on the "Sequence" array represents the number of elements in the array. Within the developed framework, the size represents how many steps are desired to simulate the assembly process. GameObjects with elements to represent each subsequent step of the assembly process are connected to the subsequent "Element" within the array in the order that the assembly components would be put in place.

\begin{tabular}{|c|c|c|c|}
\hline \multirow{4}{*}{$\begin{array}{r}\text { Size }=\# \text { of object groups/steps in } \\
\text { sequence of simulation }\end{array}$} & \multicolumn{3}{|c|}{ Sequence } \\
\hline & Size & \multicolumn{2}{|l|}{23} \\
\hline & Element 0 & Foundation & $\odot$ \\
\hline & Ementent 1 & SillPlate & $\odot$ \\
\hline Model & Element 2 & FloorJoists & $\odot$ \\
\hline Foundation & Element 3 & SubfloorSheathing & $\odot$ \\
\hline SillPlate & Element 4 & WallFraming & $\odot$ \\
\hline FloorJoists & Element 5 & Wallsheathing & $\odot$ \\
\hline WallFraming & Element 6 & RoofTrusses & $\odot$ \\
\hline Wallsheathing & Element 7 & Roofsheathing & $\odot$ \\
\hline RoofTrusses & Element 8 & Roofshingles & $\odot$ \\
\hline RoofSheathing & Element 9 & RidgeVent & $\odot$ \\
\hline RoofShingles & Element 10 & HVAC & $\odot$ \\
\hline RidgeVent & Element 11 & 8 Plumbing Rough In & $\odot$ \\
\hline $\begin{array}{l}D \text { HVAC } \\
\text { Plumbing }\end{array}$ & Element 12 & Exterior Windows & $\odot$ \\
\hline $\begin{array}{l}\text { Plumbing Rough In } \\
\text { Exterior Windows }\end{array}$ & Element 13 & Exterior Doors & $\odot$ \\
\hline Exterior Doors & Element 14 & Vinyl Siding & $\odot$ \\
\hline V Vinyl Siding & Element 15 & ExteriorTrim & $\odot$ \\
\hline ExteriorTrim & Element 16 & Gutter & $\odot$ \\
\hline Gutter & Element 17 & ExteriorSteps & $\odot$ \\
\hline ExteriorSteps & Element 18 & Wallinsulation & $\odot$ \\
\hline D Wallinsulation & Element 19 & RoofInsulation & $\odot$ \\
\hline RoofInsulation & Element 20 & Ceiling & $\odot$ \\
\hline Drywall & Element 21 & Drywall & $\odot$ \\
\hline Ceiling & Element 22 & Interior Doors & $\odot$ \\
\hline
\end{tabular}

components grouped as GameObjects

sequence array asset

\section{Fig. 5: Sequence GameObject array in Unity}

The next step of the C\# method is to execute the visual changes of the model based on user input when the simulation is running. This is done by using trigger keys and a counter to turn on and off the elements of the defined array (Figure 6). The simulation is controllable through mouse and keyboard functions or inputs from an $\mathrm{X}$-box style controller. One trigger key is used for increasing the counter while a second trigger key is used for decreasing the counter. As the counter is increased, the group of elements in the model that are assigned to the element with the same number in the "Sequence" array are turned to be visible. If the trigger to decrease the counter is clicked then the last group that appeared is turned off to represent the prior step of the sequence. This coding allowed for the adding of new components onto the model within the executed simulation. This allows the user to view different steps of the sequence (Figure 7). 


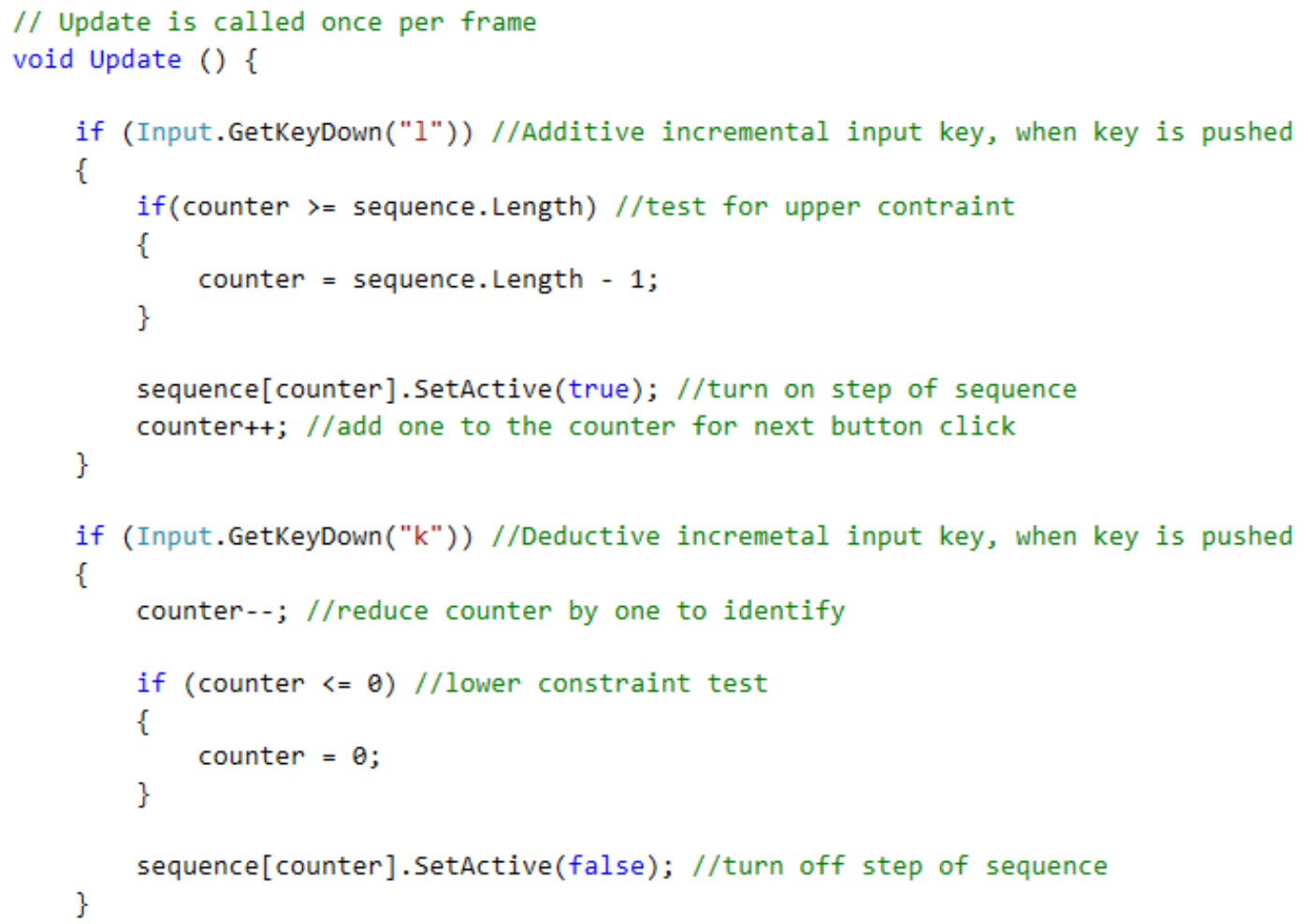

Figure 6: Update Method for changing model view

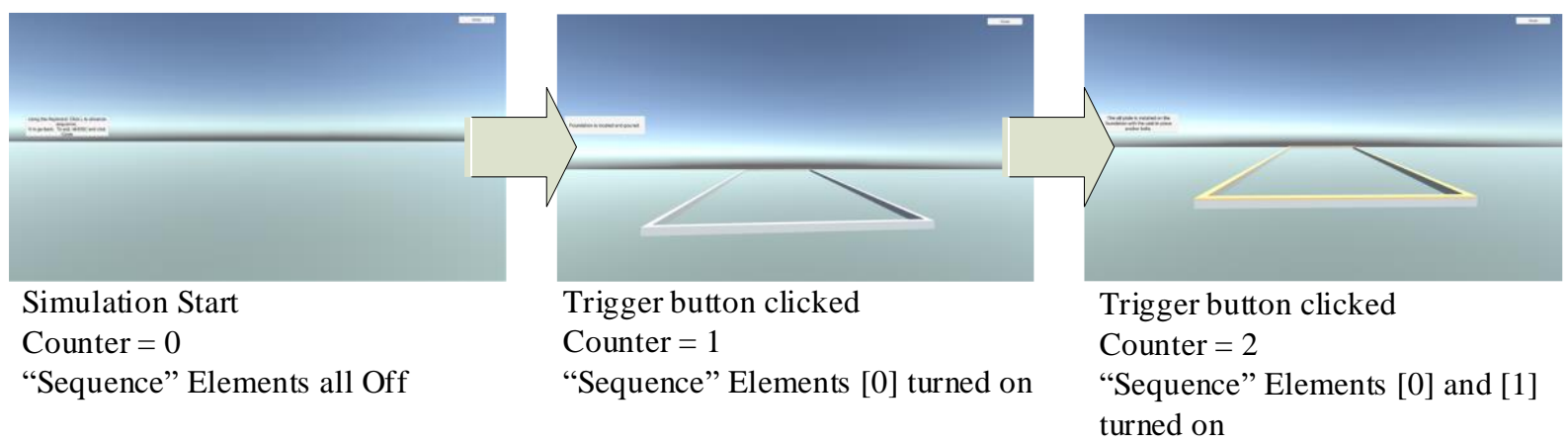

Figure 7: Sequence Progression

Additional text blocks were added to each element group with a description of each new step of the sequence. These text blocks were added over the existing text block within the GameObject connected to each element array. At this stage, the simulation can be built as an executable file to run on a desktop computer and controlled either with a mouse and keyboard or an X-box style controller.

\subsubsection{Desktop versus GearVR Development}

Deploying the simulation through an immersive headset required some modifications for the programming of the user controls. However, the programming for the sequential appearance of assembly components remained the same. The OVRPlayerController within Unity was used for navigational controls. Additional modifications were made for the trigger key controls to work with the X-box style controller utilized with the VR headset.

Initial VR testing was conducted using the Oculus Rift connected to a Dell XPS 8910. Utilizing the Rift and high powered computer to view the simulation allowed for the user to experience smooth navigation with no lag or distortion. However, once the simulation was built for use on GearVR utilizing a Samsung S7, some lag of user movement and distortion appeared. The model was too complex once fully visible to allow for easy navigation. 
The lag and distortion was a potential distraction to the user. To prevent this from being an issue with the lower powered GearVR headset additional programming was added to limit the amount of "unseen" objects within the model that were being rendered. This can be done in two ways, Occlusion Culling can be enabled. Occlusion Culling calculates which objects are visible within the camera view. If an object is hidden by another object, or occluded, it will not render in the scene. The elements of the model need to be set up to either act as an "occluder" or "occludee" or both. Having significant objects in the model would require greater processing power to determine if an object is occluded from a scene as the camera is moved. However, it will help with the power needed for rendering the object meshes that are not visible in the scene if the Occlusion Culling was not used. Depending on the size of the model and number of meshes set up to act as "occluder" elements, it can slow down the processing of the model and result in lag or distortion.

Another method is to manually determine which elements at a given stage of the simulation are visible and add custom programming. For example, once floor sheathing was in place there was no need to have the joists visible as the only way the user would see the joists is if they were under the floor which was not an option. Once the floor sheathing was put in place through the sequence method and Element [3] "Floor Sheathing" was visible, the coding turned off Element [2] "Floor Joists". This code was added to the trigger keys as an "if-then" statement (Figure 8). Additionally, once the Element [3] "Floor Sheathing" was turned off by the trigger key to go backwards in the sequence the coding turned Element [2] "Floor Joists" back to visible. For smaller models with less components, this may not be an issue and the basic framework for the simulation sequencer should work without the need for customized programming.

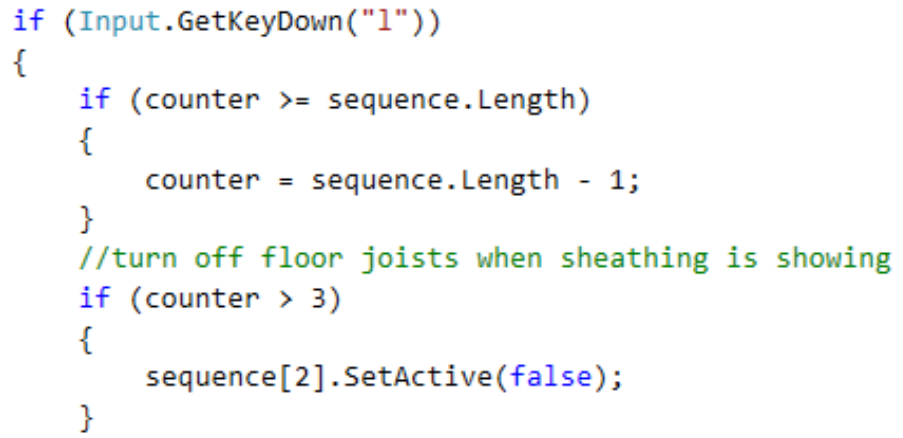

Figure 8: Hide unseen elements

Additionally, the text boxes utilized for the desktop version are not elements that render in an immersive headset. Therefore job boards were added to several locations of the simulation to allow the user to read a description of what happened in the sequence of the assembly (Figure 9). These were controlled with the same sequence method as the desktop simulation by grouping the text within the GameObject connected to the array elements. The job boards stay in the same location throughout the entire simulation but the text changes depending on the step of the sequence to describe what has happened in each step of the simulation.

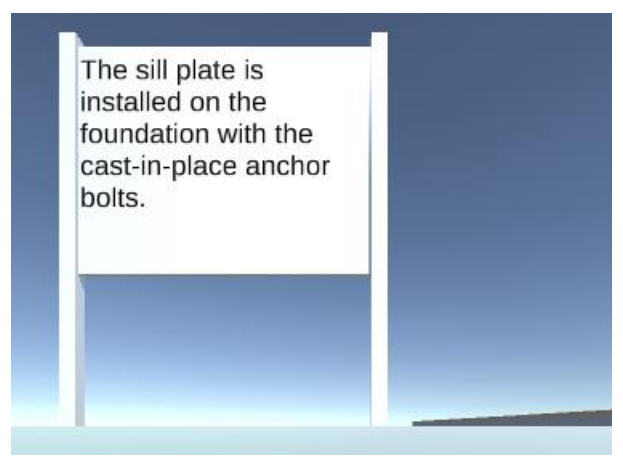

Figure 9: Job board sequence description in immersive simulation 


\subsubsection{User Navigation}

The user navigation controls for the desktop simulation were primarily the mouse and keyboard. Alternatively an X-box style controller would also work as an input device. The "l" and "k" keys on the keyboard were used as trigger keys to advance and move back through the simulation respectively. The mouse was used for moving the view angle up and down (mouse y-axis) and turning the view left and right (mouse $\mathrm{x}$-axis). The arrow keys were used for forward and backward movement of the character and the left and right keys were used to strafe the view.

For the immersive simulation usable on an HMD, head tracking, as part of the OVRPlayerController, was used to change the view of the character. The left stick on an X-box controller was used to navigate through the environment and move the character forward, backward, and left-right strife. The "A" key was used as the trigger to advance the simulation (add to the counter) while the "B" key was used to move backwards in the simulation (reduce the counter). Additionally, the directional-pad was utilized to allow the user to turn without the need for the user to physically rotate their body in the direction they wish to move. The right and left bumper buttons were also set to rotate the character in 90 degree increments in the respective direction. This function could potentially cause cyber-sickness because it does not require direct control of the user to change the view. If done too quickly, this rotation can cause sensory conflict within the cognitive processes of the brain. After further user interface and navigation testing this feature may be turned off to minimize user discomfort.

When developing user navigation controls for the simulation best practices were used to create an environment that would allow for ease of navigation and wayfinding while minimizing the risk of cyber sickness. These features included the removal of "head bob", the up-down movement of the camera to mimic the gate of someone walking in first person, which often causes added sensory conflict and results in feelings of motion sickness, inclusion of acceleration and deceleration when starting and stopping to prevent abrupt changes in motion that can cause vertigo, and limiting the maximum speed allowed for a user to move through the environment to minimize chances of discomfort. Feedback from the student population used for the preliminary study was also taken into account when designing the simulation navigation and wayfinding.

\section{INITIAL RESPONSE FROM STUDENTS}

The completed prototype sequencing simulation was taken into a Materials and Methods of Construction classroom where the students were learning about wood framing. The simulation was used to compliment the other instructional material utilized for the course. In total, there was one section of the course offered during the semester with 21 enrolled students. The course is given at the sophomore level of the program. The students are typically in their second year of the program or have transferred into the program and taking it concurrently with their introductory course. Most students would have minimal experience and exposure to wood frame construction before taking the course. A preliminary evaluation study was conducted to get initial feedback from the students on the simulation (Fig. 10). It is worth noting that findings from this study are limited do to the size of the class that was used and more extensive studies are planned in future research.

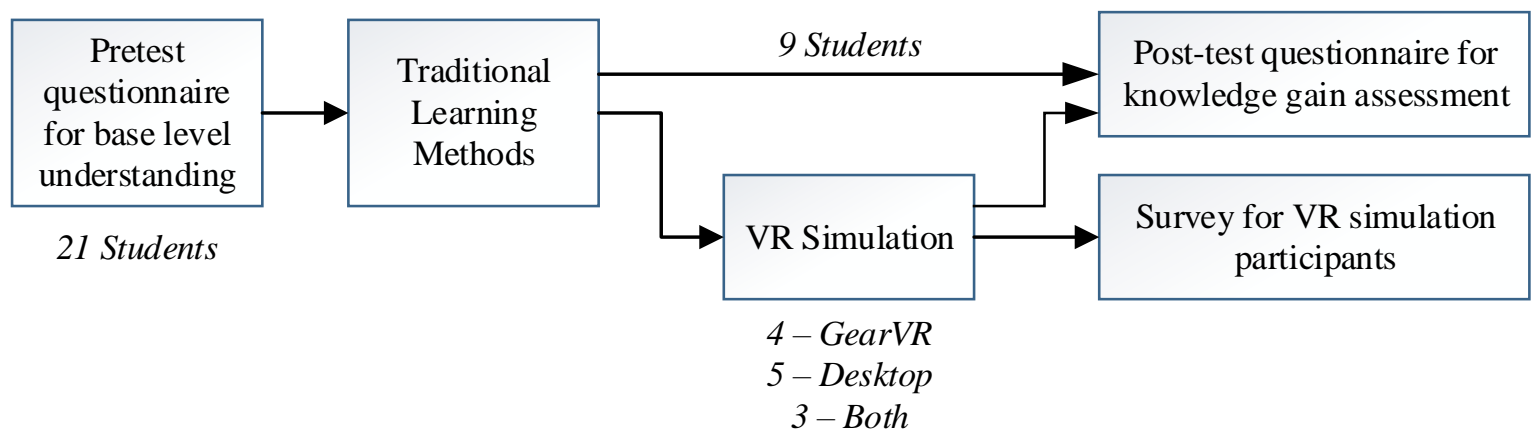

Fig. 10: Preliminary evaluation study

The 21 students were all given a pre-test before the content on sequencing wood frame construction was covered through traditional means in the class. The traditional means involved text book readings and lectures that included images and videos. Of the 21 students, 9 students did not use either of the simulations. The remaining 12 students used at least one of the simulations when reviewing the material (4 used only the GearVR, 5 used only the desktop simulation, and 3 used both). The students were all provided the opportunity to utilize either of the simulations. 
The groups were formed randomly by the student's choice to participate. Those who participated were not all considered the "strong" more motivated students based on overall class grades at the end of the semester and because of the voluntary nature to participate overall course grades were not considered as a factor during the analysis.

After the wood framing module of the course was completed a post-test activity and survey was administered to the entire class to judge any knowledge gain advantage provided by the simulations as well as gauge acceptance of the technology for this application with the students who used either simulation method. The normalized knowledge gain was calculated by using the formula:

$$
\frac{(\text { posttest } \%-\text { pretest } \%) \times 100}{(100 \%-\text { pretest } \%)}
$$

Normalized knowledge gain looks at the subject matter that the students actually learned during the course of the class. The top of the equation is the Actual Gain where the bottom of the equation is the Possible Gain. Overall the class had a 58.5\% average knowledge gain. Those who did not participate in using the simulations had a $55.2 \%$ knowledge gain while those who used at least one simulation had a $61.1 \%$ knowledge gain. Of the three subgroups of those who used the GearVR only, used the desktop simulation only, or used both, the desktop simulation use was slightly higher at $62.5 \%$ while using just the HMD or both was $60.1 \%$. Because of the small groups these results only provide promising insight that the simulations actually did have a benefit to the students' learning. These early findings are consistent with the conclusion of Jin and Nakayama (2013) who found that simulated experiences accompanying a traditional classroom base delivery of material allowed for enhanced learning by the students over a "lecture only" environment.

The students were allowed to provide open ended responses to their perceived benefit of the simulation. The students were favourable to the use of the new methods to support classroom based learning. One student even noted wishing they would have used the desktop simulation for a longer period of time to really understand the material better before the test. Several other students noted a clear benefit of exploring the environment in either simulation because it allowed them to gain a better understanding of the construction sequence and experienced it in scale with control over the environment.

When asked how well they felt the simulations helped with understanding spatial qualities as compared to the traditional in-class methods the result was a 4.3 on a 5 point Likert scale. Additionally, the simulations ability to help understand space was rated a 3.5/5, understanding components of construction a 3.87/5, and understanding the materials that were used 3.4/5. Most students felt that navigation and wayfinding in both simulations was relatively easy and user friendly with only 1 student stating they had issues with navigation in both simulations.

Because of the small response pool, the data was not statistically significant in any analysis run and is purely descriptive. The number of participants was limited to the enrolment in the course at the time the study was conducted. To get a better understanding of the affects of the VR simulation on student learning, the study will be repeated over several more iterations of the course. This will allow for more students and data to be incorporated into the study.

\section{FUTURE DEVELOPMENT AND EVALUATION}

There are two stages of future research directly related to the simulation described in this paper. The first is to further test the environment with the students according to the spatial perception questionnaire (Paes, 2017) and simulation sickness questions (Kennedy et.al, 1993) to gauge the quality of the simulated environment. This will allow for the evaluating of the simulation environment's overall design.

The second stage will be to test the ability of the students to actually learn within the environment. Though pilot testing in a small, one section class allowed for some insight, it is important to have a greater understanding as to how well the different forms of simulation can impact the students learning in this context. Ideally, three groups will be utilized. The control group will have access to the course content as it is generally taught. The remaining two groups will be exposed to one of the simulations. The first group will be allowed to have access to the desktop simulation and the second group allowed to have access to the immersive VR. A series of pre-test/post-test experiments and comparison can then be used to gauge which method may have the most influence, if at all, on students actually learning the material and understanding the sequencing of construction activities. 
Lastly, since students find perceived value in this type of simulation tool as stated in the preliminary study, additional content can easily be developed if accurate models of assemblies are created. The developed framework used for the simulation will allow for quick and efficient simulation creation if the model is created with the appropriate details and organized in a way to easily group like elements to represent steps in the process.

Assuming a positive impact, further development will be conducted of other assemblies. This will also allow for the incorporation of variations of sequences that could potentially occur. To make this available to the students, a main menu option will be developed that will allow students to examine the existing sequence versus some modifications that are also legitimate sequencing options. Additionally, more detailed pieces of the overall sequence and construction of actual assemblies can be created using the same framework but by using more detailed models to show the finer details of assemblies.

\section{CONCLUSION}

In order to enhance the experiential learning of construction management students in a Materials and Methods of Construction course VR simulation has been explored. The goal of the research was to identify a method of rapidly developing content to augment the traditional learning materials of the course. Traditional methods for experiential learning that include field trips and hands-on laboratory projects were limited due to resource and time constraints so the virtual environment was explored as a viable alternative.

To explore the feasibility of rapidly developing usable content a single model was developed. This model was used to create a framework within Unity that can be used to create additional content with new models. The framework used as many built-in functions of Unity as possible to minimize the need for customized programming with each individual model. This allowed for flexibility in creating new models and sequences. Due to the nature of the simulations and the goal of showing construction sequences, an additive nature existed allowing layers of elements to be turned on in sequence to show the progression of construction.

With the current setup of the framework, a new model can be imported into Unity as an asset. If the model was created in groups or layers within the original modelling software that corresponds with the sequences of construction a new simulation can be created within a few minutes by mapping the groups of elements to the order of the sequence array. Additional descriptions would need to be updated but this can be done similar to using a text editor and does not require programming knowledge. The programing that was completed is flexible to allow for the framework of development to work without it needing to be changed.

One of the biggest challenges faced for implementing the simulations to a non-tethered HMD, like the Samsung GearVR, is model size and processing power. If the models become too detailed and there are too many rendered elements in the model it can slow down the response time of the user movement which can increase the possibility of cyber-sickness. To combat this in the case study customized coding was utilized to shut off certain objects. This was the only area that was customized for the simulation. If smaller models are used with occlusion culling they should not slow down the processing and allow for easier use and no customized coding. Alternatively, for the desktop-based simulation or use with a tethered HMD, the Oculus Rift, larger models were not as much of an issues because of the graphic processing power provided by the computer as compared to that of a mobile device.

Though evaluation with students and actual learning impact was limited, the response from students was positive with promising results. Overall the students and faculty see value with this type of technology for this purpose. There are signs of the use of these simulations being able to increase the students' understandings of how assemblies are constructed. There is also interest outside of the materials and methods coursework where similar simulations can be used to help students in estimating and scheduling courses understand larger sequencing events. In conclusion, the hope is that the simulations can help students improve the way they learn about and plan for construction.

\section{ACKNOWLEDGEMENTS}

Portions of this study were funded by a Faculty Development Grant sponsored by the Clemson Department of Construction Science and Management Industry Advisory Board. 


\section{REFERENCES}

Boton, C. (2018). Supporting constructability analysis meetings with Immersive Virtual Reality-based collaborative BIM 4D simulation, Automation in Construction, Vol. 96, 1-15.

Cho, C.S., Mazze, C.E., Dika, S.L., and Gehrig, G.B. (2015). Enhancing Construction Education: Implementing Habitat for Humanity Projects as Service-Learning for Construction Materials, International Journal of Construction education and Research, Vol. 11, No. 1, 4-20, DOI: 10.108/15578771.2014.915274

Dennison, M.S., Wisti, A.Z., and D'Zmura, M. (2016). Use of physiological signals to predict cybersickness, Displays, Vol. 44, 42-52.

Davis, K.S. and Cline, R.C. (2009). Improving Course Comprehension through Experiential Learning, Proc. Of 2009 Construction Research Congress, 1409-1418.

Douglas-Lenders, R.C., Holland, P.J., and Allen, B. (2017). Building a better workforce: A case study in management simulations and experiential learning in the construction industry, Education + Training, Vol. 59, No. 1; 2-14, https://doi.org/10.1108/ET-10-2015-0095

Fogarty, J., El-Tawil, S., and McCormick, J. (2015). Exploring structural behavior and component detailing in virtual reality, Proc. Structures Congress 2015, ASCE Reston, VA, 2557-2564.

Freina, L. and Ott, M. (2015). A literature review on immersive virtual reality in education: State of the art and perspectives, Proc. 11 th International Scientific Conference, eLearning and Software for Education (eLSE), NDU Publishing House, Bucharest, 133-141.

Hamzehh, F., Theokaris, C., Rouhana, C., and Abbas, Y. (2017). Applications of hand-on simulation games to improve classroom experience, European Journal of Engineering Education, Vol. 42, No. 5, 471-481, DOI: 10.1080/03043797.2016.1190688

Hegazy, T., Abdel-Monem, M., Saad, D.A., Rashedi, R. (2013). Hands-On Exercise for Enhancing Students' Construction Management Skills, Journal of Construction Engineering and Management, Vol. 139, No. 9 , $1135-1143$.

Hilfert, T., Teizer, J., Konig, M. (2016). First Person Virtual Reality for Evaluation and Learning of Construction Site Safety, Proc. 33rd International Symposium on Automation and Robotics in Construction (ISARC 2016), Curran Associates, Inc. Red Hook, NY.

Jaiswal, N., Ray, W., Slobounov, S. (2010). Encoding of visual-spatial information in working memory requires more cerebral efforts than retrieval: evidence from EEG and virtual reality study, Brain Research, Vol. $1374,80-89$.

Jin, G. and Nakayama, S. (2013). Experiential Learning through Virtual Reality: Safety Instruction for Engineering Technology Students, Journal of Engineering Technology, Vol. 30 No. 2,16-23.

Kennedy, R.S., Lane, N.E., Berbaum, K.S., and Lilienthal, M.G. (1993). Simulator Sickness Questionnaire: An Enhanced Method for Quantifying Simulator Sickness, The International Journal of Aviation Psychology, Vol. 3, No. 3, 203-220.

Kwon, C. (2018). Verification of the possibility and effectiveness of experiential learning using HMD-based immersive VR technologies, Virtual Reality, (In Press, Vol. 2018): https://doi.org/10.1007/s10055-0180364-1

LaViola, J.J. (2000). A discussion of cybersickness in virtual environments, SIGCCHI Bulletin, Vol. 31, No. 1, 47-56.

Le, Q.T., Pedro, A., Park, C.S. (2014), A Social Virtual Reality Based Construction Safety Education System for Experiential Learning, Journal of Intelligent Robotic Systems, Vol. 79, 487-506: DOE 10.1007/s10846014-0112-Z

Lin, Y., Chen, Y., Yien, H., Huang, C., and Su, Y. (2018). Integrated BIM, game engine and VR technologies for healthcare design: A case study in cancer hospital, Advanced Engineering Informatics, Vol. 36, 130-145. 
Lucas, J. (2018a). Student Perceptions and Initial Response to using Virtual Reality for Construction Education, Proc. International Conference for the Associated Schools of Construction, ASC, Fort Collins, CO., 281288.

Lucas, J. (2018b). Exploring Immersive VR in the Construction Classroom to Increase Student Understanding of Wood Frame Construction, Journal of Information Technology in Construction (Itcon), vol. 23, 179-194, http://www.itcon.org/2018/9

Luo, Y. and Chhabda, J.S. (2018). Design and Implementation of a Virtual Lab in an Engineering Laboratory Course, Proc. International Conference for the Associated Schools of Construction, ASC, Fort Collins, CO., 176-182.

Ma, Z. and Xia, B. (2017). Research on Dynamic Simulation of Virtual Reality Technology in Landscape Architecture Construction, Revista de la Facultad de Ingenieria, Vol. 32, No. 5, 733-741.

Maghool, S.A.H., Moenini, S.H., and Arefazar, Y. (2018). An Educational Application Based on Virtual Reality Technology for Learning Architectural Details: Challenges and Benefits, ArchNet: International Journal of Architectural Research, Vol. 12, No. 3, 246-272.

Messner, J., Yerrapathruni, S., Barata, A., and Whisker, V. (2003). Using Virtual Reality to Improve Construction Engineering Education, Proceedings of the 2003 American Society for Engineering Education Annual Conference \& Exposition, ASEEm Washington, D.C.

Moore, J.D. and Plugge, P.W. (2008). Perceptions and Expectations: Implications for Construction Management Internships, International Journal of Construction Education and Research, Vol. 4, No. 2, 82-96: DOI: $10.1080 / 15578770802229433$

Paes, D., Arantes, E., and Irizarry, J. (2017). Immersive environment for improving the understanding of architectural 3D models: Comparing user spatial perception between immersive and traditional virtual reality systems, Automation in Construction, Vol. 84, 292-303.

Pariafsai, F. (2016). Effectiveness of a Virtual Project-Based Simulation Game in Construction, International Journal of Scientific Research in Science, Engineering, and Technology, Vol. 2, No. 5, 377-393.

Pedro, A., Le, Q.T., and Park, C.S. (2016). Framework for integrating safety into construction methods education through interactive virtual reality, Journal of Professional Issues of Engineering Education and Practice, Vol. 142, No. 2, 04015011.

Repetto, C., Serino, S., Macedonia, M., Riva, G. (2016). Virtual Reality as an Embodied Tool to Enhance Episodic Memory in Elderly, Frontier Psychology, Vol. 7, 1839. doi 10.3389/fpsyg.2016.01839.

Roussou, M., Oliver, M., and Slater, M. (2006). The virtual playground: an educational virtual reality environment for evaluating interactivity and conceptual learning, Virtual Reality, 10, 227-240.

Sacks, R. Perlman, A. and Barak, R. (2013). Construction safety training using immersive virtual reality, Construction Management and Economics, Vol. 31, No. 9, 1005-1017.

Sala, N.M. (2016). Emerging Tools and Applications of Virtual Reality in Education, ed. Choi, D.H., DaileyHerbert, A., and Estes, J.S. IGI Global, Hershey PA USA.

Sampaio, A., Ferreira, M., Rosario, D., Martins, O. (2010). 3D and VR models in Civil Engineering education: Construction, rehabilitation, and maintenance, Automation in Construction, Vol. 19, No. 7, 819-828.

Shu, Y., Huang, YZ, Chang, SH, Chen, MU. (2018). Do virtual reality head-mounted displays make a difference? A comparison of presence and self-efficacy between head-mounted displays and desktop computerfacilitated virtual environments. Virtual Reality: S.I.: VR In Education, (In Press, Vol. 2018): https://doi.org/10.1007/s10055-018-0376-X

Winn, W., Windschitl, M., Fruland, R., and Lee, Y. (2002). When does immersion in a virtual environment help students construct understanding. Proc. of the International Conference of the Learning Sciences, ICLS, 497-503.

Zhao, D. and Lucas, J. (2015). Virtual reality simulation for construction safety promotion, International Journal of Injury Control \& Safety Promotion, Vol. 22, No. 1, 57-67. 